\title{
Communications
}

\section{Profile of presenting states of eyes in angle-closure glaucoma}

\author{
D. A. LEIGHTON, G. I. PHILLIPS, AND S. TSUKAHARA \\ From the Department of Ophthalmology, University of Manchester, and Manchester Royal Eye \\ Hospital
}

It seems to be often believed that most cases of closed-angle glaucoma present in the acute state, while chronic cases are uncommon. It was our impression that chronic closed-angle glaucoma as a presenting state is quite frequent and also that it accounts for a high proportion of patients with apparently unilateral glaucoma, i.e. one eye having pathological cupping of the disc and raised ocular tension, the other eye having a normal optic disc and ocular tension.

Our interest in this subject also arose because occlusion of the central retinal vein and thrombotic glaucoma were found in some patients to be associated with closed-angle glaucoma. (Their connection with open-angle glaucoma is well known.) Thrombotic glaucoma is often difficult to distinguish from absolute closed-angle glaucoma, but in both conditions the fellow eye usually provides an important clue to the diagnosis.

An assessment was therefore made of the state of presenting and fellow eyes of 77 patients with closed-angle glaucoma; these were all the new patients who presented with this diagnosis to the Professorial Unit of Manchester Royal Eye Hospital between January, I966, and July, ig69. We consider that the frequency distribution of types to be presented is probably a representative sample, because only two patients with this particular disease were referred from other consultant surgeons: one had bilateral and the other unilateral chronic closed-angle glaucoma.

The criteria mentioned in the classification below are often not absolute so that some overlap between categories must be admitted. Arabic numerals are used to present eyes and corresponding roman numerals to present fellow eyes.

(1) and (i) Acute and subacute closed-angle glaucoma Constant features were ocular pain, raised ocular tension, corneal oedema, and shallow anterior chamber.

(2) and (ii) Chronic closed-angle glaucoma Raised ocular tension ( $>21 \mathrm{~mm}$. $\mathrm{Hg}$ ) and gonioscopically closed angles were invariably present. Ocular pain and corneal oedema were either absent or minimal.

(3) and (iii) Intermittent angle-closure glaucoma Symptoms of recurrent blurring of vision and "glaucomatous" haloes were present, but at the time of examination the ocular tension was normal and the angles of the anterior chambers were open but narrow and predisposed to angle-closure. 
(4) and (iv) Angle-closure glaucoma associated with

(a) Central or tributary retinal vein occlusion

(b) Thrombotic glaucoma

(c) Absolute closed-angle glaucoma

These three conditions have been included together because it is often very difficult to differentiate

$(b)$ from $(c)$, while of course $(b)$ is necessarily associated with $(a)$.

(5) and ( $v$ ) Angle-closure induced by mydriatic eye drops

(6) and (vi) Asymptomatic but judged to be predisposed to angle closure on gonioscopy, e.g. "fellow eyes" with no symptoms and normal ocular tension.

(7) and (vii) Asymptomatic and considered normal

\section{Results and comments}

The state of presenting and fellow eyes in the 77 patients included in this survey is recorded in Table I. The Figure shows the frequency of the various types of closed-angle glaucoma in presenting eyes. Females ( 58 or 75.3 per cent.) outnumbered males ( 19 or $24 \cdot 7$ pero cent.). Duke-Elder ( 1969 ) mentions that closed-angle glaucoma is commoner in females. Surprisingly, the average age of the males was $5^{8 \cdot 8}$ years and that of the females $67 \cdot 6$ years.

(I) Acute and subacute closed-angle glaucoma in:

(A) PRESENTING EYES

These comprised surprisingly only 39 (50.6 per cent.) of the 77 cases. There were fewer. males (8) than females (31); difference significant at $\mathbf{P}<0.001$ using the Sign test (Siega

Table I

Type of closed-angle glaucoma

\begin{tabular}{|c|c|c|c|}
\hline \multicolumn{4}{|c|}{ Presenting } \\
\hline \multicolumn{4}{|l|}{ Sex } \\
\hline \multirow[b]{2}{*}{ Male } & \multirow[b]{2}{*}{ Female } & Total & \\
\hline & & No. & $\begin{array}{l}\text { Per } \\
\text { cent. }\end{array}$ \\
\hline 8 & $3^{1}$ & 39 & $50 \cdot 6$ \\
\hline 8 & 16 & 24 & $3^{1 \cdot 2}$ \\
\hline o & 6 & 6 & $7 \cdot 8$ \\
\hline 3 & 2 & 5 & $6 \cdot 5$ \\
\hline $\mathbf{o}$ & 3 & 3 & $3 \cdot 9$ \\
\hline I9 & $5^{8}$ & 77 & 100 \\
\hline
\end{tabular}

\begin{tabular}{|c|c|c|c|c|c|}
\hline (I) & Acute and subacute & 8 & $3^{1}$ & 39 & $50 \cdot 6$ \\
\hline (2) & Chronic & 8 & 16 & 24 & $3^{1 \cdot 2}$ \\
\hline (3) & Intermittent & o & 6 & 6 & $7 \cdot 8$ \\
\hline (4) & $\begin{array}{l}\text { Associated with central retinal vein } \\
\text { occlusion } \pm \text { thrombotic glaucoma } \\
\text { or absolute closed-angle glaucoma }\end{array}$ & 3 & 2 & 5 & $6 \cdot 5$ \\
\hline （5） & Induced by mydriatic eye drops & $\mathbf{o}$ & 3 & 3 & $3 \cdot 9$ \\
\hline Tot & & 19 & $5^{8}$ & 77 & 100 \\
\hline
\end{tabular}

Fellow

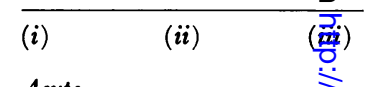

Acute
and
subacute Chronic $\quad \begin{aligned} & \text { Imter- } \\ & \text { mitter }\end{aligned}$

\begin{tabular}{lcc}
\hline 3 & & $\frac{3}{3}$. \\
\hline 0 & 5 & $0 \frac{0}{3}$ \\
\hline 0 & 12 & $\infty$ \\
\hline & 0 & $\frac{0 D}{0}$ \\
\hline
\end{tabular}



"Fellow eyes" in Groups ( $i$ ) to (vii) correspond by horizontal rows to their contralateral "presenting eyeg" 


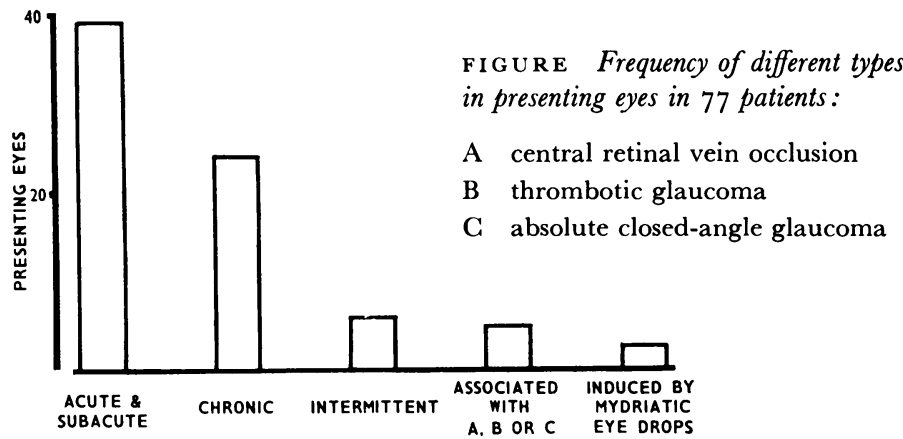

1956). Rather unexpectedly, the males were younger than the females; the mean age of males was 55.4 and that of females 70.9 years, and this difference was significant at $\mathrm{P}=0 \cdot 0023$, using a Mann-Whitney $\mathrm{U}$ test (Siegel, 1956).

(B) FELLOW EYES

The state of the fellow eye (classified as in Table I) in the 39 cases of acute closed-angle glaucoma in the presenting eye was as follows:

(iii), (v), and (vii) None.

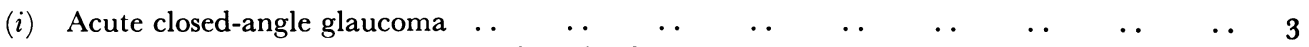
i.e. three had bilateral acute closed-angle glaucoma

(ii) Chronic closed-angle glaucoma These five fellow eyes would not have been suitable for prophylactic peripheral iridectomy

\begin{tabular}{|c|c|c|c|c|c|}
\hline \multirow{2}{*}{$\begin{array}{l}\text { ed with } \\
\text { 'etinal } \\
\text { 'usion, } \\
\text { tic, or } \\
\text { glaucoma }\end{array}$} & \multirow{2}{*}{$\begin{array}{l}(v) \\
\text { Induced by } \\
\text { mydriatic } \\
\text { eye drops }\end{array}$} & \multirow{2}{*}{$\begin{array}{l}\text { (vi) } \\
\text { Asymptomatic } \\
\text { or } \\
\text { predisposed }\end{array}$} & \multirow{2}{*}{$\begin{array}{l}\text { (vii) } \\
\text { Normal }\end{array}$} & \multicolumn{2}{|c|}{ Total } \\
\hline & & & & $\mathcal{N} o$. & $\begin{array}{l}\text { Per } \\
\text { cent. }\end{array}$ \\
\hline & o & 28 & o & 39 & $5^{0} \cdot 6$ \\
\hline & 0 & II & I & 24 & $3^{1 \cdot 2}$ \\
\hline & 0 & 6 & 0 & 6 & $7 \cdot 8$ \\
\hline & 0 & 4 & o & 5 & $6 \cdot 5$ \\
\hline & 3 & $o$ & 0 & 3 & $3 \cdot 9$ \\
\hline & $\begin{array}{l}3 \\
(3.9 \%)\end{array}$ & $\begin{array}{l}49 \\
(63.6 \%)\end{array}$ & $\begin{array}{l}\text { I } \\
(1 \cdot 3 \%)\end{array}$ & 77 & IOO \\
\hline
\end{tabular}


Table II State of optic discs and ocular tension in 24 cases of chronic closedangle glaucoma in the presenting eye

\begin{tabular}{|c|c|c|c|c|}
\hline \multicolumn{2}{|c|}{ Eyes of 24 patients } & \multirow{2}{*}{$\begin{array}{l}\text { Presenting (24) } \\
2 \mathrm{I}\end{array}$} & \multirow{2}{*}{$\begin{array}{l}\text { Fellow (24) } \\
9\end{array}$} & \multirow{3}{*}{$\begin{array}{l}\begin{array}{l}\text { Asymmetrical } \\
\text { cases }\end{array} \\
\begin{array}{l}* \\
12(50 \%)\end{array}\end{array}$} \\
\hline \multirow{2}{*}{$\begin{array}{l}\text { Optic } \\
\text { disc }\end{array}$} & $\begin{array}{l}\text { Pathological } \\
\text { cupping }\end{array}$ & & & \\
\hline & Normal & 3 & I5 & \\
\hline \multirow{2}{*}{$\begin{array}{l}\text { Ocular } \\
\text { tension }\end{array}$} & $\begin{array}{l}\text { Raised (i.e. } \\
>21 \mathrm{~mm} . \mathrm{Hg} \text { ) }\end{array}$ & 24 & I I & \multirow{2}{*}{$\begin{array}{l}* * \\
13(54 \cdot 2 \%)\end{array}$} \\
\hline & $\begin{array}{l}\text { Normal (i.e. } \\
21 \mathrm{~mm} . \mathrm{Hg} \\
\text { or less) }\end{array}$ & o & 13 & \\
\hline
\end{tabular}

*presented with one pathologically cupped disc and one normal disc

$* *$ presented with raised ocular tension $(>21 \mathrm{~mm} . \mathrm{Hg})$ in one eye and normal ocular tension (21 mm.Hg or less) in the other

(iv) Angle closure associated with central retinal vein occlusion and:

Thrombotic glaucoma ... .

Absolute closed-angle glaucoma

The three patients in Group (iv) all had symptoms in these "fellow" eyes (for 3 years, one month, and many years respectively) before the acute attack in the presenting eye्ठ developed and eventually caused them to attend an ophthalmologist. If the severe visual $I_{-}^{-}$ disturbance in what is now classified as the "fellow" eye had not been ignored, the acte attack in the "presenting "eye could have been prevented, because tonometry, goniosco and provocative tests would probably have revealed a predisposition to angle closure.

(vi) Asymptomatic but judged to be predisposed to angle closure on gonioscopy . . $\quad \ldots \quad$. 2 2\%

Without prophylactic peripheral iridectomy, the liability to signs or symptoms in fellow eyes over a period of 5 years is about 40 to 60 per cent. (Winter, I 955; Bain, 1957; Lowe, 1962; Becker and Shaffer, 1965).

(2) Chronic closed-angle glaucoma in:

(A) PRESENTING EYES

A surprisingly high number, $24\left(3^{1 \cdot 2}\right.$ per cent.) were in this group. This emphasizes theळ importance of gonioscopy which is so essential a part of the examination of both eyes of a patient with glaucoma or raised ocular tension at the first visit.

(B) FELLOW EYES

The state of the fellow eye in these 24 patients with chronic closed-angle glaucoma in the presenting eye was as follows:

(i), (iii), (iv), and (v) None.

(ii) Chronic closed angle glaucoma ..

i.e. there were twelve cases of bilateral chronic closed-angle glaucoma. 
(vi) Asymptomatic but judged predisposed to angle closure $\quad \begin{array}{llllllllllll} & \ldots & \ldots & \ldots & \ldots & & \ldots & \text { II }\end{array}$ These required prophylactic peripheral iridectomy.

(vii) Asymptomatic and normal

The last patient, a most unusual one indeed, did not require prophylactic peripheral iridectomy. Measurement of ocular dimensions in both eyes of this patient showed surprisingly little asymmetry:

\begin{tabular}{|c|c|c|}
\hline Measurements & Presenting eye & Unaffected fellow eye \\
\hline Corneal diameter $(\mathrm{mm})$. & $10 \cdot 71$ & $10 \cdot 5^{1}$ \\
\hline Corneal thickness (mm.) & $0 \cdot 6 r$ & 0.63 \\
\hline Corneal radius & $\begin{array}{l}7.54 \text { at } 10^{\circ} \\
8.10 \text { at } 100^{\circ}\end{array}$ & $\begin{array}{l}7 \cdot 70 \text { at } 170^{\circ} \\
8 \cdot 16 \text { at } 82 \cdot 5^{\circ}\end{array}$ \\
\hline Corneal astigmatism & $0 \cdot 56$ against the rule & 0.46 against the rule \\
\hline Anterior chamber depth (mm.) & $2 \cdot 34$ & $2 \cdot 43$ \\
\hline Lens thickness (mm.) & $4 \cdot 54$ & $4 \cdot 33$ \\
\hline Vitreous length (mm.) & $14 \cdot 27$ & $13 \cdot 79$ \\
\hline Axial length (mm.) & $21 \cdot 76$ & $21 \cdot 18$ \\
\hline Refraction & $+2.75 \mathrm{D}$ sph., $+5 \mathrm{D}$ cyl., axis $5^{\circ}$ & $+3.75 \mathrm{D}$ sph., $+3.75 \mathrm{D}$ cyl., axis $\mathrm{I} 75^{\circ}$ \\
\hline
\end{tabular}

However, 2 years later this apparently normal fellow eye was reclassified, on gonioscopic appearances of a narrow angle and iris bombé, as predisposed to closed-angle glaucoma and a prophylactic peripheral iridectomy was done. Perhaps a critical amount of forward displacement of the anterior surface of the lens is required before "significant" iris bombé results.

Table II shows the state of the optic discs and ocular tensions in the 24 patients who had chronic closed-angle glaucoma in the presenting eye. Half of the 24 patients had pathological cupping of the disc in the presenting eye and a normal disc in the fellow eye. This is a higher incidence of a greater degree of asymmetry than that observed by Fishman (1970) in ocular hypertension and in open-angle glaucoma ( 30 and 36 per cent.) compared with normal ( 5.6 per cent.): Fishman also mentions two cases of asymmetrical cupping in subacute angle-closure glaucoma with early field loss. The ocular tension was raised in all presenting eyes and in only three of them was the optic disc normal, indicating the advanced state of the majority of cases of chronic closed-angle glaucoma at the time of presentation. In only one patient with chronic closed-angle glaucoma and pathological cupping in the presenting eye did the angle open completely on gutt. pilocarpine, indicating that angle closure was not usually reversible (Foulds and Phillips, 1957). Eleven of the fellow eyes had raised ocular tension when first seen and eight of them had pathologica! cupping of the disc; thirteen fellow eyes had normal ocular tension, i.e. $21 \mathrm{~mm}$.Hg or less, and twelve of them had a normal disc. (Eleven were judged on gonicscopy to be predisposed to angle closure and one was normal). Very surprisingly one had normal ocular tension with an open but narrow angle, yet there was pathological cupping of the disc. This fellow eye could well have been diagnosed as a case of "low tension" glaucoma, but raised ocular tension, a closed angle, and pathological cupping of the disc were found in the presenting eye. Presumably irido-trabecular contact had existed for months or years but for some reason had resolved (Foulds and Phillips, 1957). 
(3) Intermittent angle-closure glaucoma in:

(A) PRESENTING EYES

There were six patients $(7 \cdot 8$ per cent.) in this group. They all required prophylact peripheral iridectomy. The diagnosis may be sufficiently in doubt for provocative tests to be undertaken. A most important feature of the history is that haloes are not prese every evening ( $c f$. lenticular haloes) and that they are usually associated with pain, $\overline{\mathscr{g}}$ combination which is a useful diagnostic feature.

(B) FELLOW EYES

The state of the fellow eye in these six patients with intermittent angle-closure glaucom $\vec{a}$ was as follows:

(i)-(v) and (vii) None.

(vi) Asymptomatic but predisposed to angle closure These all required prophylactic peripheral iridectomy

(4) Angle-closure glaucoma associated with:

Gentral retinal vein occlusion Thrombotic glaucoma

Absolute closed-angle glaucoma

\section{(A) PRESENTING EYES}

The one case of central retinal vein occlusion required prophylactic peripheral iridecto The presenting eye of the patient with thrombotic glaucoma was enucleated. All three presenting eyes affected with absolute closed-angle glaucoma had become completely bline

(B) FELLOW EYES

The state of the fellow eyes in this group was as follows:

(i), (iii-v), and (vii) None.

(ii) Chronic closed-angle glaucoma ..

(vi) Asymptomatic but predisposed to angle closure

The risk of closed-angle glaucoma in the four latter fellow eyes was probably eliminated by peripheral iridectomy. The group of 39 patients with acute closed-angle glaucoma $\mathrm{B}$ the presenting eye included three in which the fellow eye had previously suffered thron botic glaucoma ( I case) and absolute closed-angle glaucoma ( 2 cases). If these patients had presented at the onset of symptoms in what is now classified as the "fellow eye", the acute angle-closure attack in the presenting eye, which eventually led them to attend ajo ophthalmologist, could have been prevented by peripheral iridectomy. Although thest patients form a small proportion of those presenting with closed-angle glaucoma, the are intrinsically interesting and each one represents a potential diagnostic pitfall unlegs gonioscopy is done on both eyes on all patients presenting with central or tributary retin 1 vein occlusions, thrombotic glaucoma, and so-called absolute glaucoma. 
That central or tributary retinal vein occlusion may be a presenting symptom or sign of closed-angle glaucoma or intermittent angle closure glaucoma is often forgotten, and this diagnosis should be considered even when ocular tension is "normal"; i.e. all these patients should have gonioscopy no matter what the ocular tension. The fellow eye should of course also be examined with equal care.

Even more easily missed is a true "thrombotic" glaucoma initiated by a central retinal vein occlusion which in turn was caused by transient angle closure or a chronically closedangle. In such cases the fellow eye will usually provide the clue to the underlying diagnosis.

Still more important may be chronic closed-angle glaucoma with corneal oedema and hyperaemia of conjunctival and scleral vessels which can easily masquerade as a thrombotic glaucoma; again, the examination of the fellow eye is important, but careful assessment of the presenting eye, especially careful gonioscopy (in which true new vessels in the angle are not seen), will usually indicate the diagnosis. Although no such case was found in the present series, two patients with this condition had been seen in previous years. Sector iridectomy was safely performed in them and, although the sightless eyes remained hypertensive, the intraocular pressure was lowered and the onset of degenerative changes due to very high pressure may well have been postponed. Prophylactic peripheral iridectomy in the fellow eyes was of course the more valuable by-product of the careful evaluation of these patients.

A diagnosis of "absolute glaucoma" should always be qualified where possible by either "open angle" or "closed angle". We would emphasize that gonioscopy, even of a blind eye, is worth while, as well as in the fellow eye which may be predisposed to angle closure and require prophylactic peripheral iridectomy. The three cases of absolute closed-angle glaucoma in the presenting eye included in this series illustrate this point well. All three eyes were blind and the fellow eye was judged to be predisposed to angle closure in two cases and chronic closed-angle glaucoma was present in the third.

\section{(5) Angle closure induced by mydriatic eye drops in:}

\section{(A) PRESENTING EYES}

This group comprised three patients who all had bilateral closed-angle glaucoma. In two cases gutt. homatropine had been instilled into both eyes by an ophthalmologist. The third was an asymptomatic sister of a patient with closed-angle glaucoma who was given a gutt. eucatropine 5 per cent. water-drinking tonography test as part of a survey of relatives of patients with closed-angle glaucoma.

\section{(B) FELLOW EYES}

As mentioned above, all three patients in this group were bilaterally affected.

Iridoschisis This was present bilaterally in one patient, one eye having had an acute closed-angle attack: the other eye was judged to be predisposed to angle closure.

Iridocyclitis No case of closed-angle glaucoma was found which had been mistaken for iridocyclitis with secondary glaucoma. This pitfall is liable to occur occasionally when cells are seen in the anterior chamber; the possibility of closed-angle glaucoma unfortunately may not be considered and gonioscopy may be omitted.

No case of self-limiting disease (Phillips and Woodhouse, I963) was found. 


\section{Summary}

A survey was made of 77 patients with closed-angle glaucoma who presented to the Professorial Unit of the Manchester Royal Eye Hospital between January, I966, an July, 1969. Females (75.3 per cent.) outnumbered males $(24 \cdot 7$ per cent).

Only 39 (50.6 per cent.) had acute closed-angle glaucoma in the presenting eye; o these eight were males and $3 \mathrm{I}$ females (difference significant at $\mathrm{P}<0 \cdot 00 \mathrm{I}$ ). The average age of the males was 55.4 years and of the females 70.9 years (difference significant a? $\mathrm{P}=0 \cdot 0023$ ).

Surprisingly, $24(3 \mathrm{I} \cdot 2$ per cent.) had chronic closed-angle glaucoma in the presenting eye. Eleven of these were bilaterally affected with raised ocular tension $(>21 \mathrm{~mm} . \mathrm{Hg} \mathscr{L}$ and closed angles in both eyes. Pathological cupping of the optic discs was seen in $2 \stackrel{P}{\vec{C}}$ presenting and 9 fellow eyes.

In presenting eyes, central retinal vein occlusion was found in one, thrombotic glaucomas in one, and absolute closed-angle glaucoma in three. The fellow eye in these five patient was found on gonioscopy to be predisposed to angle closure in four cases, while chronior closed-angle glaucoma was present in the fifth. Of 39 patients with acute closed-angle glaucoma in the presenting eye, one had central retinal vein occlusion associated with thrombotic glaucoma, and two had absolute closed-angle glaucoma in the fellow eye $\frac{0}{2}$ these three patients had apparently ignored the symptoms in the "fellow" eyes.

Careful assessment of both eyes (N.B. the fellow as well as the presenting eye) by tonof metry and gonioscopy must therefore be done in all cases of glaucoma or suspected glaucom even when the ocular tension is normal, and in all cases of central (and tributary) retina 3 vein occlusion and thrombotic glaucoma. A careful differentiation between thrombotio glaucoma and chronic closed-angle glaucoma is important. Absolute glaucoma shoĝl $\overrightarrow{\mathrm{b}}$ be subdivided into open-angle and closed-angle types.

\section{References}

BAIN, W. E. s. (1957) Brit. J. Ophthal., 41, 193 BECKER, B., and SHAFFER, R. N. (1965) "Diagnosis and Therapy of the Glaucomas", 2nd ed., p. I 59

Mosby, St. Louis

DUKE-ELDER, S. (1969) "System of Ophthalmology", vol. i I, "Diseases of the Lens and Vitreous

Glaucoma and Hypotony", p. 565. Kimpton, London

Fishman, R. s. (1970) Arch. Ophthal. (Chicago), 84, 590

Foulds, w. s., and PHiLlips, c. I. (1957) Brit. F. Ophthal., 41, 208

LOWE, R. F. (1962) Ibid., 46, 64 I

SIEgEL, s. (1956) "Nonparametric Statistics for the Behavioral Sciences”, pp. 68, I I6. McGraw

Hill, New York

PHillips, c. I., and woodhouse, D. F. (1963) Brit. J. Ophthal., 47, 547

Winter, F. C. (1955) Amer. J. Ophthal., 40, 557 